\title{
Retinal sensitivity in hereditary retinal degeneration in Abyssinian cats: electrophysiological similarities between man and cat
}

\author{
K NARFSTRÖM,1 G B ARDEN, ${ }^{2}$ aND S E G NILSSON ${ }^{3}$ \\ From the 'Department of Ophthalmology, Linköping University, S-581 85 Linköping, Sweden; the \\ ${ }^{3}$ Department of Surgery, Faculty of Veterinary Medicine, Swedish University of Agricultural Sciences, S-750 07 \\ Uppsala, Sweden; and the ${ }^{2}$ Electrodiagnostic Clinic, Moorfields Eye Hospital, London
}

SUMmARY The functional and electrophysiological similarities in the changes in the electroretinogram (ERG) of man and cat affected by hereditary retinal degenerative disease were studied. The results of a series of log intensity-amplitude studies in a group of young affected Abyssinian cats were fitted to the Naka-Rushton relationship by means of a mathematical package on the University of London mainframe. The analysis showed that the amplitude of the maximum darkadapted b-wave was significantly reduced by the end of the period studied but that the value of $k$, a variable inversely equivalent to retinal sensitivity, was only slightly reduced by the retinal degenerative process. The electrophysiological findings thus are similar to those found in cases of human diffuse dominantly inherited retinitis pigmentosa.

A recessively inherited rod-cone degeneration has been described in a strain of Abyssinian cats. ${ }^{2}$ Often at the age of 1.5 to 2 years the fundus is ophthalmoscopically normal, but the end stage (blindness) occurs after another 3-4 years. Thus the progression of the disease is rather slow.

Previous electrophysiological as well as ultrastructural investigations in clinically affected adult cats $^{34}$ have shown that the photoreceptors are primarily affected in the disease, the rod system being affected prior to that of the cones. A significant reduction of scotopic a- and b-wave maximum amplitudes is seen at an early stage when only minor changes are observed by ophthalmoscopy. At this time there is no significant reduction of the c-wave amplitudes in comparison with controls, and SP recordings and $30 \mathrm{~Hz}$ flicker responses are normal.

One of the aims of investigating photoreceptor degenerations in animals is to obtain models for similar diseases in humans. Several rodent ${ }^{5-9}$ and canine $^{1011}$ retinal dystrophies have been well documented. But it is still uncertain whether these diseases are closely related to any human form of retinitis pigmentosa (RP). This is true also for the Abyssinian cat retinal degenerative disease, though

Correspondence to Dr K Narfström. several clinical and morphological similarities between the diseases in cat and human are seen. ${ }^{24}$ This paper is concerned with the functional and electrophysiological similarities in the changes of the electroretinogram (ERG) of man and cat affected by hereditary retinal disease.

\section{Material and methods}

ERGs were obtained in 10 affected and 11 control cats. The methods have been described in detail elsewhere. ${ }^{12}$ In brief, general anaesthesia was induced with sodium thiopentone and maintained with halothane; the pupils were dilated with atropine and neosynephrine. The silver-silver chloride corneal electrode was contained in a diffusing contact lens, which helped to make retinal illumination uniform. The animals were dark adapted for $\mathbf{4 5}$ minutes, after which the series of ERGs were obtained. The $20 \mathrm{~ms}$ white light flashes were produced by an electronic shutter and delivered to the eye with a fibre optic system placed in the visual axis. Intensity was varied over a range of $5 \log$ units by inserting neutral density filters in the light path. The maximum light intensity employed was 85000 lux, measured at the surface of the contact lens. The amplifier bandpass was $0 \cdot 3$ to $1000 \mathrm{~Hz}$. Responses were displayed and photo- 
a

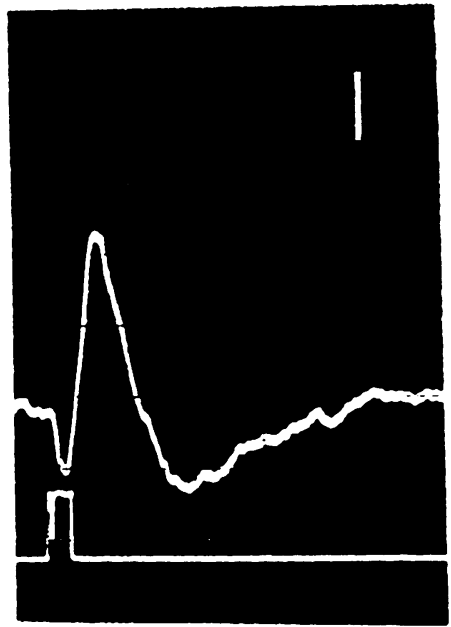

b

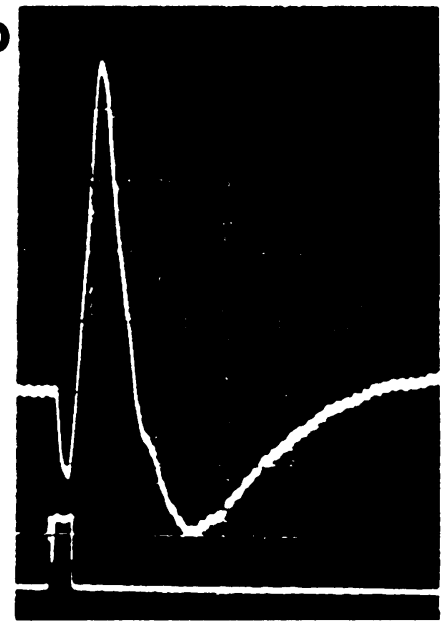

C

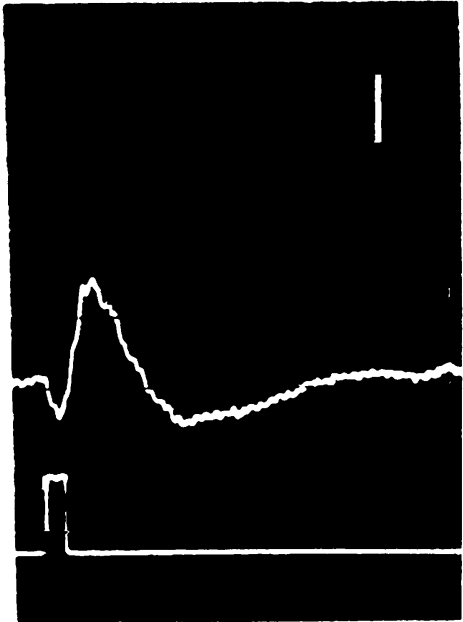

d

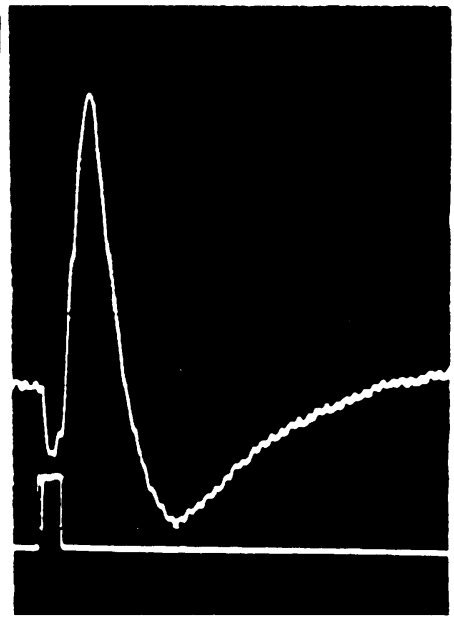

Fig. 1 Representative ERGs of (a) a 13-week-old Abyssinian kitten homozygous for hereditary retinal degeneration (affected); (b) $a$ 12-week-old control kitten; (c) a 56week-old affected Abyssinian; and (d) a 56-week-old control cat. Vertical bar for $(a)$ and $(b)=100$ $\mu V$, for $(c)$ and $(d)=50 \mu V .20 \mathrm{~ms}$ of white light stimulus (31000 lux) indicated. graphed from the screen of a storage oscilloscope. The first records were obtained at 8 weeks of age. The animals recovered from the anaesthesia and the test was repeated in several animals at intervals up to 104 weeks of age.

\section{Results}

Representative recordings are shown in Fig. 1. As already shown, ${ }^{12}$ there is no change in ERG wave form or implicit time, but the magnitude of the a- and b-waves is decreased in affected animals.

In the youngest age group (group 1;8-16 weeks) there was a significant decrease in the maximum dark adapted $b$-wave amplitude but not of the corresponding a-wave amplitude when affected cats were compared with controls. In group 2 (17-32 weeks) the a- and b-wave decreases observed were not statistically significant, probably because during this time period both the normal and the affected ERG amplitudes become reduced as the kittens' retina matures. ${ }^{13-15}$ In group 3 (33-104 weeks) both a- and b-wave maximum amplitudes were significantly reduced. The quantity of light required to elicit a criterion voltage $(50 \mu \mathrm{V})$ was determined, and for the youngest age groups there were no significant differences between affected and controls. In group 3 there was in one animal an increase in the light intensity required to elicit a criterion voltage $b$-wave.

To investigate this point in more detail we fitted the results to the Naka-Rushton relationship, ${ }^{16}$

$$
V=V_{\text {max }} \frac{I^{n}}{I^{n}+k^{n}}
$$

where $\mathrm{V}$ is the response amplitude in $\mathrm{V}, \mathrm{V}_{\max }$ is the maximum ERG amplitude, $I$ is the stimulus luminance, $\mathrm{k}$ represents the light intensity required to produce a half-maximal response, and $\mathrm{n}$ is a 
dimensionless constant that determines the slope of the function.

The best fitting results (least squares method) were obtained by an iterative procedure using the mathematical package on the University of London mainframe. Results were obtained for the normalised results of all the animals in each group, and are shown in Table 1 . The variation is the size of $V_{\max }$ was as in the previous study. ${ }^{12}$ Note that the computer prediction of the maximum b-wave amplitude was only $3-4 \%$ larger than obtained in the experiment. The values of $k$ varied slightly from group to group.

After the age of 17 weeks the value of $k$ for the affected groups was significantly less than for the normal control kittens. The value of $\mathbf{n}$ was similar for all groups, but was calculated to be considerably less than unity. Fig. 2 shows representative graphs of results from individual animals. It can be seen that the calculated functions fit the results reasonably well and that there is a real difference in the constants calculated by the computer program.

An attempt was made to analyse the a-wave data in the same way as we have analysed the b-wave data, but the computer program was unable to converge on a unique relationship.

\section{Discussion}

This analaysis has shown that the amplitude of the maximum dark adapted $b$-wave is reduced by the end of the period studied and that the value of $k$, a variable inversely equivalent to retinal sensitivity, has been slightly reduced by the retinal degenerative process. The electrophysiological findings thus are similar to those found in cases of human diffuse dominantly inherited retinitis pigmentosa, ${ }^{178}$ in which large rod ERGs are seen, and the value of $k$ is only slightly affected. In patients with such disease the visual fields are often sizeable, and large areas of retina are found with well preserved scotopic function, so that rod threshold is not raised significantly.

However, in man there are very few reports on retinal ultrastructure in dominant disease $e^{1-21}$ and none at all which relate to the state of the retinal at an early stage of the disease, when vision is only scarcely affected. Such information is available for these cats (Narfström K, Nilsson SE, in press).

Electron microscopy showed that in this strain of Abyssinian cats retinal alterations may be found in affected kittens already before the time of retinal maturation. ${ }^{22}$ In kittens aged 9 to 84 days homozygous for the defect, but still with an apparently normal retina as judged by ophthalmoscopy, there are a certain number of rod outer segments, usually less than $50 \%$ but occasionally more, that appear completely disorganised and some even disrupted. These lesions are found in a patchy distribution over the retina, and are often more frequently observed in the peripheral retina than the central parts.

It is of interest to consider whether this histological picture can be reconciled with the electrophysiological and densitometric findings in man and cat as well as with psychophysical findings in man.

If sensitivity is only slightly reduced when a considerable number of rod outer limbs are disorganised or disrupted, this is in keeping with the idea that in many cases of RP sensitivity is reduced only to the extent that the light-absorbing power of the retina is reduced-that is, its 'quantum catch'. ${ }^{1723}$ Thus, if $50 \%$ of rods are affected, sensitivity would be reduced only by $0.3 \mathrm{log}$ unit. In man and in cat ${ }^{24} 2 \mathrm{~s}$ rhodospin content and sensitivity reductions which obey this relationship have been reported.

Implicit, on this view, is the assumption that affected rods do not influence the ERG b-wave in any way: they behave as though they were absent. This need not be the case. It is possible that even if the transduction mechanisms of affected rods are abnormal the dark current is present (and light

Table 1 Pertinent results for the ERG $a$ - and b-waves for groups 1, 2, and 3. $C=$ controls cats. $A=$ affected cats

\begin{tabular}{|c|c|c|c|c|c|c|}
\hline \multirow[t]{3}{*}{ b-Wave } & \multicolumn{6}{|l|}{ Group } \\
\hline & \multicolumn{2}{|l|}{1} & \multicolumn{2}{|l|}{2} & \multicolumn{2}{|l|}{3} \\
\hline & $C$ & $A$ & $C$ & $\boldsymbol{A}$ & $C$ & $A$ \\
\hline $\begin{array}{l}V_{\max } \text { normalised } \\
V_{\max } V(S D) \\
\log k \\
n\end{array}$ & $\begin{array}{c}1.04 \\
988.0(124.0) \\
2.97(0.06) \\
0.43 \\
\end{array}$ & $\begin{array}{c}1.03 \\
581.0(13 \cdot 8) \\
2 \cdot 78(0.07) \\
0.49 \\
\end{array}$ & $\begin{array}{c}1.03 \\
450.5(34.0) \\
3 \cdot 21(0.07) \\
0.52\end{array}$ & $\begin{array}{c}1.04 \\
299 \cdot 3(27 \cdot 8) \\
2.47(0.06) \\
0.49 \\
\end{array}$ & $\begin{array}{c}1.02 \\
324.5(20.9) \\
3.13(0.06) \\
0.45\end{array}$ & $\begin{array}{c}1.03 \\
188.0(16.9) \\
2.75(0.08) \\
0.45 \\
\end{array}$ \\
\hline \multirow[t]{2}{*}{ a-wave } & \multicolumn{2}{|l|}{1} & \multicolumn{2}{|l|}{2} & \multicolumn{2}{|l|}{3} \\
\hline & $C$ & $\boldsymbol{A}$ & $C$ & $A$ & $C$ & $\boldsymbol{A}$ \\
\hline$V_{\max } V(S D)$ & $208 \cdot 0(35 \cdot 6)$ & $163 \cdot 3(21 \cdot 4)$ & $110 \cdot 8(23 \cdot 8)$ & $70 \cdot 8(13 \cdot 1)$ & $89.0(43.9)$ & $52 \cdot 1(10 \cdot 5)$ \\
\hline
\end{tabular}




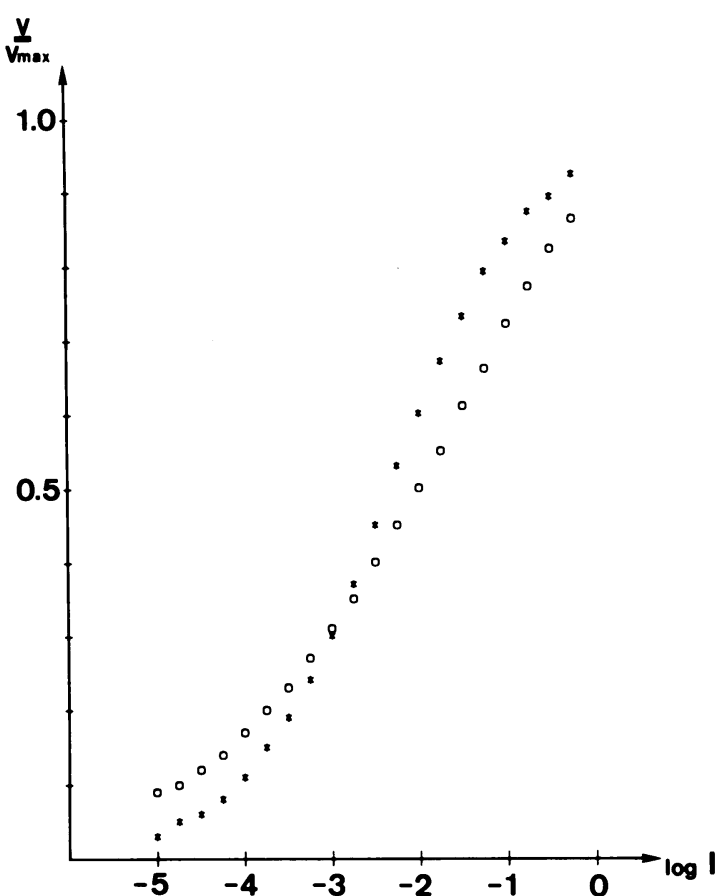

Fig. 2a

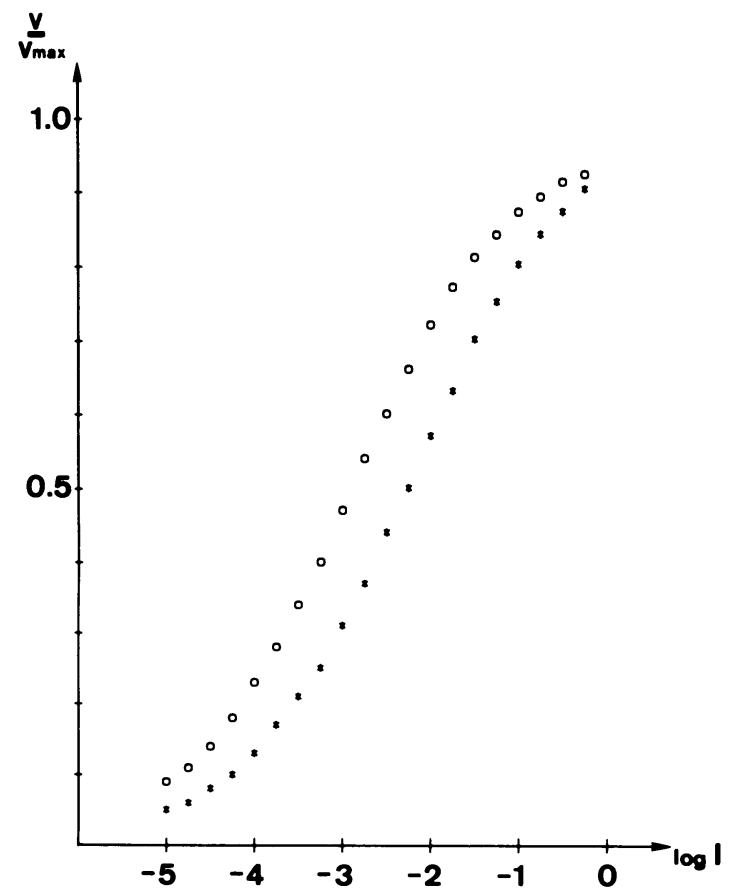

Fig. 2c

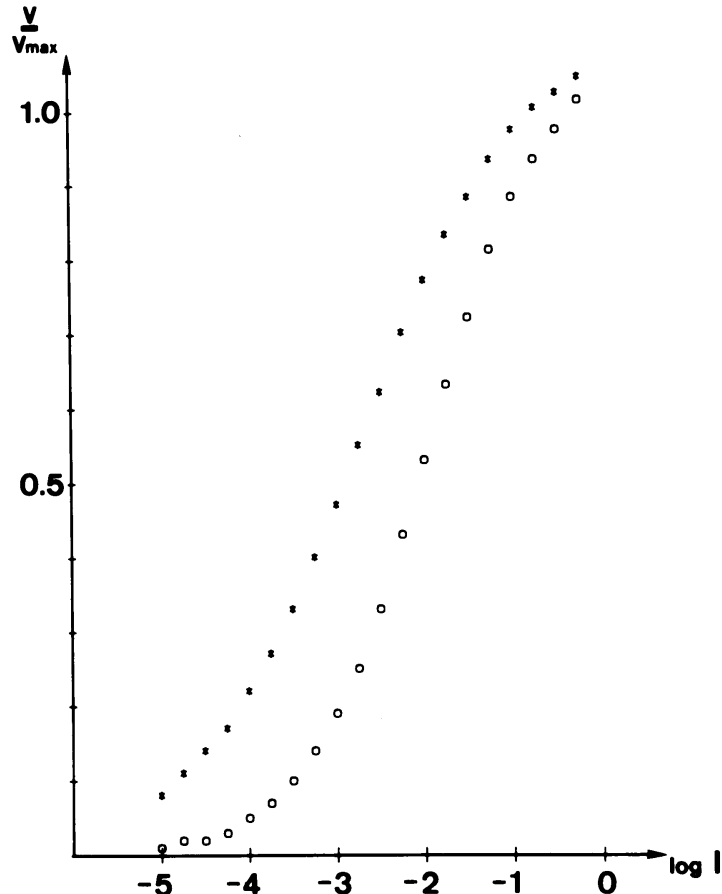

Fig. 2b

Fig. 2 Intensity-amplitude relation obtained from an affected and a control cat in each group in order to illustrate the theoretical fitting of results done by the computer. (a) Group 1: 8-16 weeks. (b) Group 2: 17-32 weeks. (c) Group 3: 33-104 weeks. Circles $=$ normal cat, stars $=$ affected Abyssinian cat.

cannot change it), so that a constant output of neurotransmitter occurs from the affected rod presynaptic terminals. Alternatively the membrane of the disorganised rod might be generally permeable but all specific ion channels and neurotransmitter channels absent. In such a case, if rods remain electrically interconnected ${ }^{26}$ when the responsive rods absorb light, the reduction in dark current would cause the cell to have to charge up a larger area of the cell membrane than in the normal eye.

What is common to all these possibilities is that the degeneration has two separate effects. If quanta fall on 'affected' rods, they are not absorbed-for the rods have vanished-or produce no excitation. Therefore sensitivity is reduced to an extent determined by the loss of rhodopsin, or by the reduction in the number of normal rods. If the quanta are absorbed in 'unaffected rods', the transduction mechanisms produce a normal electrical signal in the 
outer limb, but this signal is then 'diluted' because of the presence of the abnormal rods and produces a reduced effect at the rod synapse. The value of $k$ would increase to a greater degree than expected from counts of the number of rods lost. In addition, the linear part of the V/log I curve would extend to higher light levels in the affected animals, so the proportion of $\mathrm{V}_{\max }$ elicited by the most intense light and the value of $n$ should change. This does not occur, and therefore the results support the view that, once a rod has become affected with the disorganisation shown, it ceases to exert any influence on signal transmission. In humans clinical psychophysical studies as well as electroretinography, field tests, and dark adapted perimetry have independently led to the suggestion that a drop out of individual rods occurs. ${ }^{17} 182327$

In both man and cat the maximum b-wave is reduced. In man this reduction is related to the decrease in the area of functioning retina, as defined by perimetry. In cats of the ages we investigated there are no large areas where all rods are lost. Because the bipolar cells integrate rod activity over a relatively large area, a loss of only a proportion of their input which reduces sensitivity should not reduce the number of b-wave generators, and thus, unless some other factor intervenes, $V_{\max }$ should remain unchanged. It is known that the b-wave is produced by Müller cells. One possibility is that all the cells of a group which are invested by a particular Müller cell become inactive at the same time. Alternatively, the reduction in the number of rods alters the environment of the Müller cell and stops it generating a maximal current.

The clinical and laboratory findings in the retinal degenerative disease in this strain of Abyssinian cats shows that it is distinct from other reported RP-like diseases in dogs and rodents. The very slow time course of the degeneration and the fact that a reduction in ERG amplitudes occurs without major loss of retinal sensitivity is thus remarkably similar to the findings in some types of human disease. ${ }^{28}$ Specifically, in dominantly inherited human $\mathrm{RP}^{17}$ the value of $\mathbf{k}$ is somewhat increased, with a reduced maximum b-wave amplitude, in just the same way as in affected Abyssinian kittens.

The authors are indebted to Maria Wilén, Lillemor Abersten, and Björn-Erik Andersson for excellent laboratory and technical assistance. The work was supported by grants from the Swedish Medical Research Council (No. 12X-734), Kronprinsessan Margaretas Arbetsnämnd för Synskadade, and the Retinitis Pigmentosa Foundation Fighting Blindness, USA.

\section{References}

1 Narfström K. Progressive retinal atrophy in the Abyssinian cat. Svensk Veterinärtidning 1981; 33: 147-50.

2 Narfström K. Retinal degeneration in a strain of Abyssinian cats: a hereditary, clinical, electrophysiological and morphological study. Linköping University Medical Dissertations 1985: No. 208.

3 Narfström K, Nilsson SEG, Andersson B-E. Progressive retinal atrophy in the Abyssinian cat. Studies of the DC-recorded electroretinogram and the standing potential of the eye. Br J Ophthalmol 1985; 69: 618-23.

4 Narfström K, Nilsson SEG. Progressive retinal atrophy in the Abyssinian cat: electron microscopy. Invest Ophthalmol Vis Sci 1986; 27: 1569-76.

5 Dowling JE, Sidman RL. Inherited retinal dystrophy in the rat. J Cell Biol 1962; 14: 73-109.

6 LaVail MM, Sidman RL. C57BL/6J mice with inherited retinal regeneration. Arch Ophthalmol 1974; 91: 394-400.

7 Sanyal S, Bal AK. Comparative light and electron microscopic study of retinal histogenesis in normal and rd mutant mice. Z Anat Entwickl Gesch 1973; 142: 219-38.

8 Mullen RJ, LaVail MM. Two new types of retinal degeneration in cerebellar mutant mice. Nature 1975; 258: 528-30.

9 van Nie R, Ivanyi D, Demant P. A new H-2-linked mutation, rds, causing retinal degeneration in the mouse. Tissue Antigens 1978; 12: $106-8$.

10 Aguirre G. Inherited retinal defenerations in the dog. Ophthalmology 1976; 81: OP667-76.

11 Aguirre G, O'Brien P, Alligood J, Buyukmihci N. Pathogenesis of progressive rod-cone degeneration in the miniature poodle. Invest Ophthalmol Vis Sci 1982; 23: 610-30.

12 Narfström K, Wilén $M$, Andersson B-E. Hereditary retinal degeneration in the Abyssinian cat: developmental studies using clinical electroretinography. Doc Ophthalmol in press.

13 Vogel M. Postnatal development of the cat's retina. Adv Anat Embryol Cell Biol 1978; 54: 1-66.

14 Ikeda H, Jacobson SG. Cone and rod electroretinograms during development in the cat. J Physiol (Lond) 1982; 329 (proc): 21-2.

15 Hamasaki DI, Maguire GW. Physiologic development of the kitten's retina: an ERG study. Vision Res 1985; 25: 1537-43.

16 Naka K, Rushton WAH. The generation and spread of S-potentials in fish (Cyprinidae): J Physiol (Lond) 1970; 192: 437-61.

17 Arden GB, Carter RM, Hogg CR, et al. . Rod and cone activity in patients with dominantly inherited retinitis pigmentosa: comparison between psychophysical and electroretinographic measurements. Br J Ophthalmol 1983; 67: 405-18.

18 Lyness AL, Ernst W, Quinlan MP, et al. A clinical psychophysical and electroretinographic surveys of patients with autosomal dominant retinitis pigmentosa. Br J Ophthalmol 1985; 69: 326-39.

19 Kolb H, Gouras P. Electron microscopic observations of human retinitis pigmentosa dominantly inherited. Invest Ophthalmol Vis Sci 1974; 13: 487-98.

20 Rodrigues MM, Wiggert B, Hackett BS, Lee L, Fletcher T, Chader GT. Dominantly inherited retinitis pigmentosa. Ultrastructural and biochemical analysis. Ophthalmology 1985; 92: 1165-72.

21 Duval T, McKechnie NN, Lee WR, Rockey S, Marshall J. Extensive subretinal pigment epithelial deposit in two brothers suffering from dominant retinitis pigmentosa. Graefes Arch Clin Exp Ophthalmol 1986; 224: 299-305.

22 Narfström K, Nilsson SEG. Hereditary retinal degeneration in a strain of Abyssinian cats: developmental studies. Invest Ophthalmol Vis Sci 1987; 28 (suppl): 141

23 Massof RW, Finkelstein D. Two forms of autosomal dominant primary retinitis pigmentosa. Doc Ophthalmol 1981; 51: 289346.

24 Faulkner DJ, Kemp CM. Human rhodopsin measurements using a TV-based imaging fundus reflectometer. Vision Res 1984; 24: 221-31.

25 Kemp CM, Jacobson SG, Narfström K, Nilsson SEG. Rhodopsin levels and rod sensitivity in Abyssinian cats with retinal degeneration. Invest Ophthalmol Vis Sci 1986; 27 (suppl): 311. 
26 Attwell D. Ion channels and signal processes in the outer retina. $J$ Exp Physiol 1986; 71: 497-536.

27 Jacobson SG, Voigt WJ, Parel J-M, et al. Automated light- and dark-adapted perimetry for evaluating retinitis pigmentosa. Ophthalmology 1986; 93: 1604-11.
28 Birch DG, Fish GE. Rod ERGs in children with hereditary retinal degeneration. J Pediatr Ophthalmol Strabismus 1986; 23: 227-32.

Accepted for publication 28 October 1988. 